\title{
A prevalence survey of multiple sclerosis in Sussex
}

\author{
Margaret Rice-Oxley, Edward S Williams, J E Rees
}

\begin{abstract}
A first survey of the Brighton and MidDowns health districts in Sussex showed a prevalence of multiple sclerosis of 111 per $100000(95 \%$ confidence interval (95\% CI) 103-120) in a population of 596594 on prevalence day, 1 July 1991. Cases were notified by multiple sources and to maximise case notification patients were not contacted. Cases were classified by hospital and family practitioner notes. The Poser criteria were used for classification. These criteria are precise and exclude cases of isolated spinal cord syndrome. The Allison and Millar criteria used in the surveys in Scotland may lack specificity and it is concluded that the high prevalence of multiple sclerosis in Scotland needs to be reassessed with the more precise criteria. Until this is done, the latitude effect within the United Kingdom remains not proved.
\end{abstract}

$(\mathcal{F}$ Neurol Neurosurg Psychiatry 1995;58:27-30)

Keywords: multiple sclerosis; prevalence survey

The evidence for a north-south gradient in the distribution of multiple sclerosis in the United Kingdom has come mainly from surveys undertaken in Scotland. In the 1950s, Sutherland ${ }^{1}$ surveyed northern Scotland and reported that multiple sclerosis was more common in Scotland than elsewhere in the United Kingdom, thereby supporting the idea of a latitudinal effect. Further evidence for a gradient within the United Kingdom has been provided by the surveys of north east Scotland, ${ }^{2-5}$ which reported higher overall prevalence rates than areas surveyed in the south of England. ${ }^{6}$

In reporting their findings of a survey of multiple sclerosis in a south London borough, however, Williams and McKeran ${ }^{7}$ concluded that the evidence of a north-south gradient in prevalence in the United Kingdom was less than convincing. It has been suggested that the high prevalence in Scotland may be an effect of repeated studies and that the prevalence of the first north east Scotland survey was not significantly different from the first surveys of Sutton, Wales, and Southampton..$^{7-9}$

A key question that faces those who attempt to interpret the results reported in prevalence studies is the comparability of the findings. A close examination of the more recent United Kingdom surveys ${ }^{7-9}$ shows a significant difference in the proportion of cases classified into the "possible" group (the group with the greatest degree of diagnostic uncertainty). Roberts et $a l,{ }^{9}$ in reporting the findings of the Southampton survey, commented on the particularly high rate of "possible" cases in north east Scotland-19\% in the 1980 survey compared with $7 \%$ in Southampton.

One explanation for the differential in "possible" cases is that the diagnostic criteria of Allison and Millar (which are based on clinical findings alone) ${ }^{10}$ have been interpreted differently, thereby introducing a systematic diagnostic bias.

Another explanation is that there was a differential in the prevalence of isolated spinal cord syndrome-with higher rates in northeast Scotland-as these cases would normally be classified as "possible" cases by the Allison and Millar criteria. The Poser criteria, ${ }^{11}$ on the other hand, recognise this source of potential diagnostic error and so seek to exclude isolated spinal cord syndrome even in the presence of oligoclonal banding in the CSF.

The aim of our prevalence study of a large population in the south of England was to eliminate diagnostic bias as far as possible by using the Poser criteria and so exclude isolated spinal cord syndrome cases from the prevalence data.

\section{Subjects and methods}

SOURCES OF CASE ASCERTAINMENT

The survey populations chosen were the Brighton and Mid-Downs Health Districts, extending from latitude $50^{\circ} 4^{\prime} \mathrm{N}$ to $51^{\circ} 5^{\prime} \mathrm{N}$, and longitude $0^{\circ} 10^{\prime} \mathrm{W}$. The combined midyear estimates for 1991 gave a population denominator of 596594 (Brighton 310894 and Mid-Downs 285 700).

Approval was obtained for the study from the local Health District ethical committees.

A provisional nominal list of cases who may have a diagnosis of multiple sclerosis was created from a copy of discharge summaries from Hurstwood Park Neurological Centre (servicing the Brighton and Mid-Downs Health Districts), which had been kept in a diagnostic file since 1972. All the summaries were examined and any case with a postal address in the population area mentioning the possibility of multiple sclerosis or unexplained spinal cord syndrome was added to the provisional list. 
All general practitioners in the area were asked for information and reminders were sent to those who did not reply. Those who did not respond were sent a list of patients who were thought to be registered with them, and asked to add cases to the list or to confirm that they had no further cases. Local branches of the multiple sclerosis society, Action Research for Multiple Sclerosis, community nurses, and the Nursing Home Inspectorate were asked to provide information. South West and South East Thames Korner data were obtained. Hospital activity analysis data were only accessible for South East Thames (Brighton Health District). The attendance records of the Donald Wilson Rehabilitation Centre, Chichester were examined to ascertain possible cases. The nuclear magnetic scan result book at the neurological centre was examined for cases who might not have been admitted. Patients attending outpatient neurology clinics or attending private consultations with JER were notified throughout the course of the study.

\section{METHOD}

The Family Health Services of East Sussex for the Brighton patients and the West Sussex Family Health Services for the Mid-Downs patients established patient status on prevalence day, 1 July 1991. The 1991 mid-year estimate, based on the latest census data, was used for the denominator. Care was taken to adhere to the health district boundaries provided by the Public Health departments. Patients normally resident in the area who moved to nursing homes outside the area but were sponsored by local social services were deemed prevalent. Those who lived in nursing homes in the area but were sponsored by other social services were deemed to be nonprevalent. This proved important in Brighton, which has the John Howard House (Putney Home for Incurables).

Hospital case notes were examined to classify patients according to the criteria of the Poser committee. Only one author (MR-O) classified cases. Some patients could not be classified from hospital notes. In these cases, a request was made to the general practitioner to allow examination of the primary health care notes. The Poser criteria exclude patients with an age of onset above 59 years. To be comparable with the Southampton survey, we included these patients, but we did not accept abnormalities on MRI as paraclinical evidence for multiple sclerosis in older patients. The presence of oligoclonal banding in CSF was used to classify patients in the laboratory supported group, even if these had not been compared with serum samples, as was the practice in our neurological centre before October 1989. It is not known whether previous studies have required oligoclonal bands to be present only in spinal fluid when supplementing the clinical diagnosis with paraclinical information.

The data for Brighton and Mid-Downs were analysed separately as we were aware that there were differences in the referral pat- terns between the two districts. Provided that there were no significant differences between the areas, our intention was to combine the data to increase the statistical power of the study. It was decided to use the age-sex specific rates of this study as the standard population for calculating the standardised prevalence ratio, adapting the method of Williams and McKeran. ${ }^{7}$ We used 10 year age bands.

\section{Results}

The provisional list reached 1240 cases. In 129 cases the diagnosis was rejected. There were 133 untraced cases, and 54 cases who had died before 1 July 1991. Sixty two cases had moved out before prevalence day, and one had moved in after. Twenty nine cases were diagnosed after 1 July 1991, and 22 cases lived outside the boundaries or were supported by social services outside the boundaries. This left 810 suspected cases. One hundred and forty five cases did not fulfil the Poser criteria, leaving 665 cases that were resident in the survey area on prevalence day, producing an overall prevalence rate of 111 per 100000 .

There were seven cases with age of onset over 59. If these are excluded to adhere to the strict Poser criteria, the prevalence is 110 per 100000 (95\% confidence interval $(95 \% \mathrm{CI})$ 102-119). There were no significant differences between the Brighton and Mid-downs data when analysed separately, and only the combined data are considered further. Table 1 summarises the prevalence rates by diagnostic categories of the Poser criteria.

The laboratory definite group contained 16 cases $(38 \%)$ with a negative serum sample for oligoclonal bands. The strict interpretation of the Poser criteria requires negative serum samples, to be certain that the oligoclonal bands are intrathecally produced. We consider that this omission in some cases is not clinically important, as it is rare to find oligoclonal bands in the serum now that it has become routine practice to check for them.

There were 191 males giving a rate per 100000 males of $66 \cdot 2$ (95\% CI 57-76), and 474 females, rate 154 per 100000 females (95\% CI 140-168). The age range of the prevalent cases was $16-87$ years with a mean (SD) of $48.6(13.4)$ years. The mean (SD) age at onset of symptoms was $33 \cdot 1(10 \cdot 1)$ years (range 14-68 years). The mean (SD)

Table 1 Prevalence of multiple sclerosis in Brighton and Mid-Downs health districts by diagnostic category

\begin{tabular}{lcc}
\hline & No (\%) & $\begin{array}{l}\text { Prevalence per } \\
100000 \\
(95 \% \mathrm{CI})\end{array}$ \\
\hline $\begin{array}{l}\text { Diagnostic group } \\
\begin{array}{l}\text { Clinically definite } \\
\text { multiple sclerosis }\end{array}\end{array}$ & $528(79)$ & $89(81-96)$ \\
$\begin{array}{l}\text { Laboratory definite } \\
\text { multiple sclerosis }\end{array}$ & $42(6)$ & $7(5-9)$ \\
$\begin{array}{l}\text { Clinically supported probable } \\
\text { multiple sclerosis }\end{array}$ & $91(14)$ & $15(12-18)$ \\
$\begin{array}{l}\text { Laboratory supported probable } \\
\text { multiple sclerosis }\end{array}$ & $4(0.6)$ & $0.7(0-1)$ \\
\begin{tabular}{l} 
Total \\
\hline
\end{tabular} & $665(100)$ & $111(103-120)$ \\
\hline
\end{tabular}


Table 2 Age and sex specific prevalence of multiple sclerosis per 100000 in Brighton and Mid-Downs health districts

\begin{tabular}{|c|c|c|c|c|c|}
\hline \multirow[b]{2}{*}{ Age group } & \multicolumn{2}{|c|}{ Male } & \multicolumn{2}{|c|}{ Female } & \multirow{2}{*}{$\frac{\text { Total }}{\text { Rate }(95 \% \text { CI })}$} \\
\hline & No & Rate $(95 \%$ CI) & No & Rate $(95 \%$ CI) & \\
\hline $\begin{array}{l}15-24 \\
25-34 \\
35-44 \\
45-54 \\
55-64 \\
65-74 \\
75+\end{array}$ & $\begin{array}{r}2 \\
21 \\
56 \\
59 \\
27 \\
20 \\
6\end{array}$ & $\begin{array}{c}5(0-12) \\
43(25-61) \\
132(97-166) \\
181(135-227) \\
96(60-131) \\
85(48-122) \\
36(7-64)\end{array}$ & $\begin{array}{r}6 \\
69 \\
129 \\
120 \\
75 \\
57 \\
18\end{array}$ & $\begin{array}{c}15(3-27) \\
146(112-180) \\
309(256-362) \\
360(296-424) \\
245(190-300) \\
188(139-237) \\
54(29-79)\end{array}$ & $\begin{array}{c}10(3-17) \\
94(74-113) \\
220(188-251) \\
271(232-311) \\
173(140-207) \\
143(111-175) \\
48(29-67)\end{array}$ \\
\hline All & 191 & $66(57-76)$ & 474 & $154(140-168)$ & $111(103-120)$ \\
\hline
\end{tabular}

duration was $15.5(10 \cdot 7)$ years with a range of less than one year to 53 years.

The response rate of the general practitioners was $100 \%$ in both Brighton and Mid-Downs after persistent requests for information. General practitioners were the only source of information in $20 \%$ of cases. Permission was obtained from general practitioners to visit two cases in Brighton and three in Mid-Downs whose notes were missing or incomplete.

Table 2 presents the age and sex specific rates for the combined health districts. Table 3 compares our data with United Kingdom surveys that have used the Poser criteria. The comparative surveys all gave their overall prevalence rates with the Allison and Millar classification, which tends to produce a higher rate than the Poser classification. The standardised prevalence ratio has been recalculated for these papers with the age specific rates of this survey as the standard. The estimated annual incidence rate was calculated by the method of Poskanzer et al. ${ }^{12}$ With the seven year period from 1978 to 1984 for age of onset there were 195 cases, giving an estimated annual incidence of five per 100000 (95\% CI 3-7) for the combined area. The denominator population was adjusted using the mid-year estimates for 1978 to 1984 . The mean estimated duration of disease from onset to death was calculated by doubling the mean duration of the disease on prevalence day. The estimated duration for the combined area was 31 years. There were 145 "suspected" cases who did not fulfil the Poser criteria and, therefore, were excluded from the main analysis. These included 52 spinal cord syndromes, 40 cases with only one attack of possible demyelination, and 53 cases with recurrent attacks, which were excluded because of lack of physical signs and no

Table 3 Comparison of prevalence studies using Poser criteria

\begin{tabular}{|c|c|c|c|c|}
\hline & $\begin{array}{l}\text { South Wales } \\
1985\end{array}$ & $\begin{array}{l}\text { Southampton } \\
1987\end{array}$ & $\begin{array}{l}\text { Cambridge } \\
1990\end{array}$ & $\begin{array}{l}\text { Brighton/ } \\
\text { Mid-Downs } \\
1991\end{array}$ \\
\hline $\begin{array}{l}\text { Cases } \\
\text { Population }\left(\times 10^{3}\right) \\
\text { Prevalence (Poser) }\end{array}$ & $\begin{array}{l}381 \\
377 \\
101 \cdot 1 \\
(92-112)\end{array}$ & $\begin{array}{l}395 \\
417 \\
94 \cdot 7 \\
(88-107)\end{array}$ & $\begin{array}{l}322 \\
288 \\
112 \\
(99-124)\end{array}$ & $\begin{array}{l}665 \\
597 \\
111 \\
(103-120)\end{array}$ \\
\hline $\begin{array}{l}\text { Prevalence } \\
\quad \text { (Allison and Millar) } \\
\text { Mean age } \\
\text { Mean age of onset } \\
\text { Mean duration } \\
\text { Sex ratio }\end{array}$ & $\begin{array}{l}117 \\
(106-128) \\
49 \\
32 \\
16 \cdot 5 \\
2 \cdot 0\end{array}$ & $\begin{array}{l}98 \cdot 6 \\
(89 \cdot 3-108 \cdot 9) \\
48 \cdot 6 \\
32 \cdot 6 \\
15 \cdot 7 \\
2 \cdot 1\end{array}$ & $\begin{array}{l}129 \cdot 7 \\
(117-143) \\
49 \cdot 2 \\
29 \cdot 6 \\
19 \cdot 2 \\
2 \cdot 5\end{array}$ & $\begin{array}{l}129 \\
(120-138) \\
48 \cdot 6 \\
33 \cdot 1 \\
15 \cdot 5 \\
2 \cdot 5\end{array}$ \\
\hline $\begin{array}{l}\text { Standardised } \\
\text { prevalence ratio }\end{array}$ & $\begin{array}{l}94 \\
(85-104)\end{array}$ & $\begin{array}{l}85 \\
(76-93)\end{array}$ & $\begin{array}{l}101 \\
(90-113)\end{array}$ & $\begin{array}{l}100 \\
(92-108)\end{array}$ \\
\hline
\end{tabular}

Values in parentheses are $95 \%$ CIs. confirmatory evidence or attacks that were only in a single site.

\section{Discussion}

Our survey of Sussex covered a population of almost 600000 and found 665 cases that fulfilled the Poser criteria, giving a prevalence of 111 per 100000 (95\% CI 103-120). The advantage of surveying a large population was that the prevalence is precise with narrow confidence limits. The prevalence recorded in Sussex was remarkably similar to rates reported in the recent Cambridge survey (112 per 100000$)^{13}$ and not significantly different from the rates reported in south east Wales $(101 \cdot 1)^{8}$ and Southampton $(94 \cdot 7) .^{9}$ All recent surveys in the south of the United Kingdom have reported similar rates, and it is reasonable to conclude that the true rate in the south is just over 100 per 100000 .

For an epidemiological survey of multiple sclerosis to produce reliable results, the methods of measurement must be rigorous. This is especially important because case definition in multiple sclerosis is, to a large degree, dependent on clinical observation and so prone to a high risk of observer variation, which may lead to systematic diagnostic bias. To minimise diagnostic error and to allow the legitimate comparison of survey results, the method of case classification must be valid and repeatable.

A valid method of case classification should be sensitive in that it correctly identifies a high proportion of true cases and specific in that it yields few cases that are false positives. United Kingdom surveys that have used both the Poser and Allison and Millar classification systems have all identified a higher number of cases with the Allison and Millar system (table 3). The Cambridge survey, ${ }^{13}$ for example, identified $16 \%$ more cases. The most likely explanation for this variation is that the Allison and Millar system falsely classifies cases that resemble multiple sclerosis, such as isolated spinal cord syndrome and familial degenerations. It can be estimated from the 145 cases that did not fulfil the Poser criteria, excluding the 40 cases who had only a single attack of demyelination, that the crude Allison and Millar rate for our survey is 129 (95\% CI 120-138), with a "possible" group of isolated spinal cord syndromes contributing $52(7 \%)$ cases, similar to the Southampton survey. ${ }^{9}$

Repeatability, which is the level of agreement between replicate measures of the same population, has been poor in multiple sclerosis prevalence surveys. Repeat surveys of north east Scotland, ${ }^{2-5}$ for example, reported an increase in prevalence of $40 \%$ (from 127 to 178 per 100000 ) over 10 years. As this variation is unlikely to be due to a true increase in the frequency of the disease, it may indicate inherently inconsistent methods of measurement or observer variation. (A repeat survey of south east Wales ${ }^{14}$ did not change the prevalence after three years.) The Poser criteria were, of course, formulated after the pioneering work of the early Scottish surveys. 
We are concerned that the Allison and Millar criteria lack specificity and may lead to a systematic overestimate of the true rate. It is important to consider whether previous surveys, which used only the Allison and Millar classification, were affected by this lack of specificity. The three north east Scotland surveys used the Allison and Millar classification but applied the criteria differently in all the surveys. The 1970 survey classifies the "Early or Latent" group separately, but in the 1974 survey they become amalgamated in the "Clinical Probable" group, boosting the prevalence from 70 per 100000 to 105 . Yet Allison and Millar had created the "Early or Latent" category because they could not accord these cases the same degree of diagnostic certainty as the "Clinical Probable" group. The 1980 survey allowed "Early" cases to be classified in the "Clinical Probable" group if there was supporting evidence from paraclinical tests or raised immunoglobulins in CSF. The details, however, are not supplied in such a way that another survey could apply the criteria in the same way. It is unclear into which group spinal cord syndromes with raised immunoglobulins were classified. We conclude that north east Scotland surveys lack specificity and repeatability.

Surveys in the Shetland and Orkney Islands ${ }^{1516}$ raised the possibility of a high prevalence in the north of the United Kingdom. Yet this series of repeat surveys was based on very small populations, which produce wide confidence limits. Surveys carried out in the Orkney Islands between 1954 and 1974 produced a dramatic rise in prevalence of over $300 \%$ (from 82 per 100000 to 258 for probable cases). ${ }^{11516}$ The authors ${ }^{16}$ conclude that this rise in prevalence, which did not occur in the neighbouring Shetlands, was due to increasing survival. They tried to find a more plausible explanation, such as differential migration, but failed. They mention better treatment of infections as a reason for increased survival, but this would not explain the disparity between the Orkneys and Shetlands. The possibility that the increase was due to observer variation or diagnostic error was not discussed, and cannot be excluded.

Because of the methodological problems we have discussed, it is not possible to make legitimate comparisons between the prevalence reported in surveys of the south with those reported in north east Scotland and the surveys in the Orkney and Shetland Islands. Scotland has the highest prevalence of multiple sclerosis in the world. There will be continued interest in an area of high prevalence, in the hope that aetiological factors can be identified. For instance, resources have been spent in testing hypotheses in Scotland, such as the study on the role of HLA tissue types. ${ }^{17}$ Skegg et $a l^{18}$ have suggested that the prevalence of multiple sclerosis in New Zealand accords with the distribution of the population of Scottish ancestry, as reflected by the distribution of "Macs" and "Mcs" in the telephone directories.

There have now been several independent surveys in the south of the United Kingdom confirming the prevalence of multiple sclerosis in the south. All the Scotland surveys have been in the north east and off shore islands, and it is time for an independent survey from another area in Scotland, using the Poser criteria to add an important point on the United Kingdom prevalence map.

Until this is done, the true prevalence of multiple sclerosis in Scotland remains uncertain and the "latitude" effect within the United Kingdom is not proved.

We acknowledge the help of Mary Wallis and John Hutchings of the East and West Sussex Family Health Services; Jean Pope and Derek Agate of Medical Records; Dave Rickards, computer manager; A Millar and J C Oram, community nurses; the secretaries of all the local multiple sclerosis and Action Research for Multiple Sclerosis groups; and Dr S Nurick, Julie Lawrence, and Amanda Carss for secretarial help. The statistical help of J Edwards, SAS consultant, was invaluable. The manuscript was typed by Mary Wallis, invaluable. The manuscript was typed by Mary Wallis, been possible without the co-operation of the general practibeen possible without the co-
tioners and practice managers.

This study was funded by the Multiple Sclerosis Society of Great Britain and Northern Ireland (grant holder Professor DAS Compston).

1 Sutherland JC. Observations on the prevalence of multiple sclerosis in northern Scotland. Brain 1956;79:635-54.

Shepherd DI, Downie AW. Prevalence of multiple sclerosis in north east Scotland. BMF 1978;ii:314-6.

3 Shepherd DI, Downie AW. A further prevalence study of multiple sclerosis in north east Scotland. $f$ Neurol multiple sclerosis in north east

4 Downie AW, Phadke JG. The Chief Scientist reports...Multiple sclerosis in north east Scotland. Health Bull (Edinb) 1984;42/43:151-6.

5 Phadke JG, Downie AW. Epidemiology of multiple sclerosis in the north east (Grampian region) of Scotland-an update. F Epidemiol Community Health 1987;41:5-13.

6 Hargreaves ER. Epidemiological studies in Cornwal Proceedings for the Society of Medicine 1961;54:209-16.

7 Williams ES, McKeran RO. Prevalence of multiple sclerosis in a south London borough. $B M F$ 1986;293:237-9.

8 Swingler RJ, Compston DAS. The prevalence of multiple sclerosis in south east Wales. $f$ Neurol Neurosurg Psychiatry 1988;51:1520-4.

9 Roberts MHW, Martin JP, McLellan DL, McIntoshMichaelis SA, Spackman AJ. The prevalence of multiple sclerosis in the Southampton and South West Hampshire Health Authority. $f$ Neurol Neurosurg Psychiatry 1991;54:55-9.

10 Allison RS, Millar JHD. Prevalence and familial incidence of disseminated sclerosis. (A report to the Northern of disseminated sclerosis. (A report to the Northern
Ireland Authority on the results of a three years survey) Ireland Authority on the results of a
Ulster Med $\mathcal{f} 1954 ; 23$ (suppl 2):5-22.

11 Poser CM, Patey DW, Scheinberg L, McDonald WI, Davis FA, Ebers GC, et al. New diagnostic criteria for multiple sclerosis: guidelines for research protocols. $A n$ Neurol 1983;13:227-31.

12 Poskanzer DC, Schapira K, Miller H. Epidemiology of multiple sclerosis in the counties of Northumberland and Durham. I Neurol Neurosurg Psychiatry 1963;26: 368-76.

13 Mumford CJ, Fraser MB, Wood NW, Compston DAS. Multiple sclerosis in the Cambridge Health District of East Anglia. F Neurol Neurosurg Psychiatry 1992;55: 877-82.

14 Hennessy A, Swingler RJ, Compston DAS. The incidence and mortality of multiple sclerosis in south east Wales. $\mathcal{F}$ Neurol Neurosurg Psychiatry 1989;52:1085-9.

15 Fog M, Hyllested K. Prevalence of disseminated sclerosis in Faroes, the Orkneys and Shetland. Acta Neurol Scand in Faroes, the Orkneys and

16 Poskanzer DC, Prenny LB, Sheridan JL, Kondy JY. Multiple sclerosis in the Orkney and Shetland Islands. Epidemiol Community Health 1980;34:229-39.

17 Francis DA, Batchelor JR, McDonald WI, et al. Multiple sclerosis in north-east Scotland. An association with HLA-DQw1. Brain 1987;110:181-96.

18 Skegg DCG, Corwin PA, Craven RS, Malloch JA, Pollack $M$. Occurrence of multiple sclerosis in the north and south of New Zealand. $\mathcal{F}$ Neurol Neurosurg Psychiatry 1987;50:134-39. 